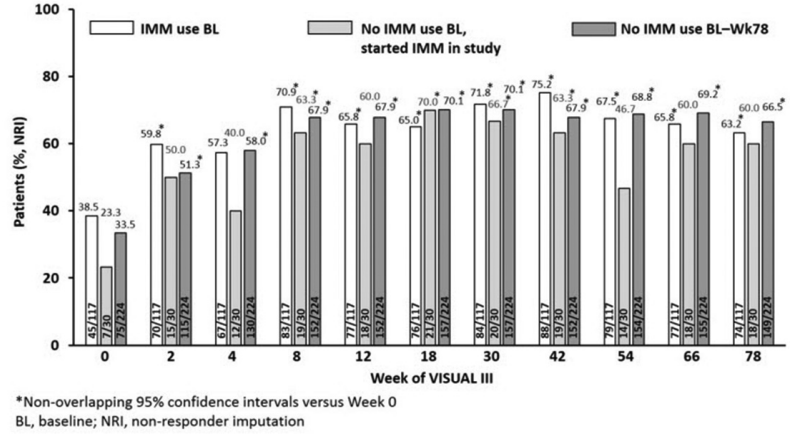

Abstract OP0086 - Figure 1. proportion of patients in quiescence by IMM use in VISUAL III

Conclusions: Exploratory analyses from the VISUAL III trial demonstrated that efficacy in adalimumab-treated patients was sustained or improved through 78 weeks of treatment, irrespective of IMM use. AE rates were consistent with previous VISUAL trials, although numerically higher rates for a subset of AEs were observed in patients taking IMM.

Acknowledgements: AbbVie funded the study and participated in study design, data analysis, and interpretation. AbbVie funded the research and provided writing support. All authors contributed to the development of the content. The authors and AbbVie reviewed and approved the abstract; the authors maintained control over the final content. Kevin Hudson, PhD, of 2theNth, provided medical writing support, which was funded by AbbVie Inc.

Disclosure of Interest: Y. Guex-Crosier Consultant for: AbbVie, Santen, and Novartis, C. S. Foster Grant/research support from: Alcon, Aldeyra, Bausch and Lomb, Clearside Biomedical, Dompe, Icon, Novartis, Santen, Xoma, Aciont, and pSivida, Consultant for: Aldeyra, Bausch and Lomb Surgical, EyeGate, Novartis, pSivida, and Xoma, Speakers bureau: Alcon and Allergan, K. Nakai: None declared, H. Goto Consultant for: AbbVie, K. Douglas Shareholder of: AbbVie, Employee of: AbbVie, S. Pathai Shareholder of: AbbVie, Employee of: AbbVie, M. Kron Shareholder of: AbbVie, Employee of: AbbVie, A. P. Song Shareholder of: AbbVie, Employee of: AbbVie, J. Van Calster Consultant for: Consultant for: advisory boards for AbbVie, Allergan, Santen, and MSD, and has served as a consultant for AbbVie, Allergan, and MSD, A. Adán Consultant for: advisory boards for AbbVie, Santen, Allergan, and Novartis

DOI: 10.1136/annrheumdis-2018-eular.2551

\section{OP0087 INCREASED RISK OF ISCHAEMIC HEART DISEASE AND MORTALITY AMONG FMF PATIENTS - PERSPECTIVE FROM A BIG DATABASE}

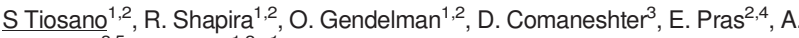
D. Cohen ${ }^{3,5}$, H. Amital ${ }^{1}, 2.1$ Internal Medicine ' $B$ ', Sheba Medical Center, TelHashomer, Ramat-Gan; ${ }^{2}$ Sackler School of Medicine, Tel-Aviv University; ${ }^{3}$ Chief Physician's office, Clalit Health Services, Tel-Aviv, ${ }^{4}$ Genetic Institute, Sheba Medical Center, Tel-Hashomer, Ramat-Gan; ${ }^{5}$ Siaal Research Center for Family Medicine and Primary Care, Faculty of Health Sciences, Ben-Gurion University of the Negev, Beer-Sheva, Israel

Background: Familial Mediterranean fever (FMF) is a systemic autoinflammatory monogenic disease. It has been previously reported that FMF patients are prone to develop ischaemic heart disease (IHD), ${ }^{1}{ }^{2}$ mostly due to increased inflammatory activity and endothelial dysfunction. ${ }^{3}{ }^{4}$ However, large-scale information regarding the extent and prognosis of IHD among FMF patients is lacking.

Objectives: To check whether an association exists between FMF and IHD, and to assess the long-term prognostic significance of IHD among FMF patients using a big data registry with a 15 year follow-up period.

Methods: Utilising the medical records of Clalit Health Services, the largest HMO in Israel, we extracted a cohort of FMF patients along with their age-and-sex matched controls. Dates of registration in the medical records of FMF, IHD and death, as well as anthropometric information and medical comorbidities were extracted from the database. To compare the distribution of variables across the cohort strata, univariate analysis was performed using Chi-square and student ttest. Multivariate analysis using a logistic regression model was used to find variables associated with IHD. Survival analysis using Cox proportional hazards method and a log-rank test was performed to find variables associated with increased risk of all-cause mortality.

Results: The cohort included 7,670 FMF patients and 7670 age-and-sex matched controls. The mean age of both groups was 39.1, and both consisted $50.1 \%$ females. IHD was observed among $491 \mathrm{FMF}$ patients $(6.4 \%)$ vs 375 controls $(4.89 \%), p<0.001$. In multivariate logistic regression, FMF was found to be independently associated with a diagnosis of IHD (OR 1.44, 95\% Cl: 1.21 to 1.72). After over 15 years of follow-up, $345(4.5 \%)$ of FMF patients had died, compared to $271(3.53 \%)$ of the controls $(p<0.001)$. In multivariate survival analysis both FMF and IHD were found to be significantly associated with increased risk to all-cause mortality (HR 1.29, 95\% Cl: 1.10 to 1.53 and HR $1.57,95 \%$ Cl: 1.29 to 1.9 , respectively)

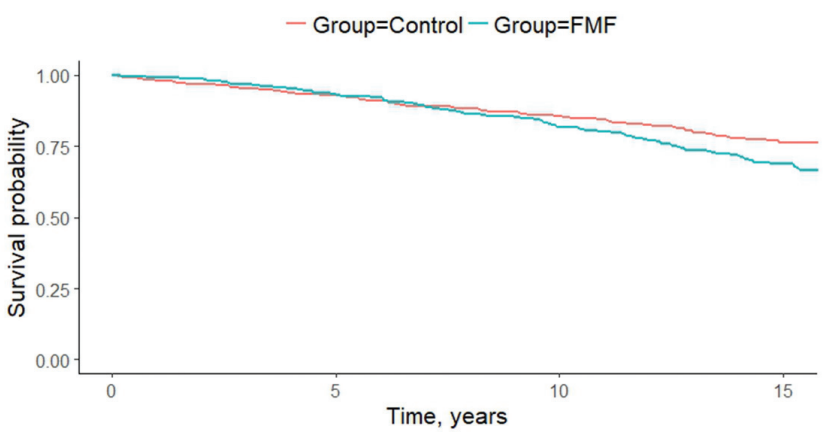

Conclusions: IHD is associated with worse prognosis among FMF patients compared to controls. Proper screening methods are recommended to assess whether early identification and treatment may improve life expectancy.

\section{REFERENCES}

[1] Langevitz P, Livneh A, Neumann L, et al. Prevalence of ischemic heart disease in patients with familial Mediterranean fever. Isr Med Assoc J IMAJ 2001;3:9-12.

[2] Twig G, Livneh A, Vivante A, et al. Cardiovascular and metabolic risk factors in inherited autoinflammation. J Clin Endocrinol Metab 2014;99: E2123-E2128. doi:10.1210/jc.2014-2096

[3] Akdogan A, Calguneri M, Yavuz B, et al. Are Familial Mediterranean Fever (FMF) patients at increased risk for atherosclerosis? Impaired endothelial function and increased intima media thickness are found in FMF. J Am Coll Cardiol 2006;48:2351-2353. doi:10.1016/j.jacc.2006.09.013

[4] Sari I, Karaoglu O, Can G, et al. Early ultrasonographic markers of atherosclerosis in patients with familial Mediterranean fever. Clin Rheumatol 2007;26:1467-1473. doi:10.1007/s10067-006-0529-2

Disclosure of Interest: None declared

DOI: 10.1136/annrheumdis-2018-eular.4768

\section{OP0088 IMMUNE-RELATED ADVERSE EVENTS OF CANCER IMMUNOTHERAPY - WHEN INFLAMMATORY SIDE EFFECTS ARE ASSOCIATED WITH SURVIVAL: A SINGLE-CENTRE PROSPECTIVE COHORT STUDY}

M. Kostine, E. Mauric, L. Rouxel, T. Barnetche, R. Veillon, F. Martin, C. Dutriaux, L. Dousset, A. Pham-Ledard, S. Prey, M. Beylot-Barry, A. Daste, M. Gross-Goupil, J. Lallier, A. Ravaud, E. Forcade, B. Bannwarth, M.-E. Truchetet, C. Richez, N. Mehsen-Cetre, T. Schaeverbeke, on behalf of the FHU ACRONIM. Bordeaux University Hospital, Bordeaux, France

Background: Immune checkpoint inhibitors (ICl) represent a new standard of care for the treatment of selected advanced cancers and are still being investigated in many other tumour types. By enhancing the T-cell activation, a unique spectrum of inflammatory side effects has emerged, also known as immunerelated adverse events (irAEs), including various well-described rheumatic manifestations. Data regarding the association between irAEs and patient outcomes are conflicting.

Objectives: To evaluate the incidence and characteristics of irAEs in patients receiving $\mathrm{ICl}$, as well as the correlation with tumour response and patient survival. Methods: This was a single-centre prospective observational study including all cancer patients receiving ICls. The occurrence of irAEs, tumour response and patient outcomes were assessed on a regular basis. Overall survival has been considered from the start of $\mathrm{ICl}$.

Results: From May 2015 to September 2017, 636 patients (70\% male, mean age 64 years) have been included in this cohort while receiving anti PD-1 $(n=435)$, ant PD-L1 $(n=66)$ or anti CTLA-4 $(n=3)$ as single agent or as sequential $(n=100)$ or combined $(n=32)$ therapies. Cancer types were mainly melanoma $(n=293)$, nonsmall cell lung cancer $(n=150)$ and renal carcinoma $(n=83)$. Overall, $274 / 633$ patients $(43 \%)$ experienced irAEs, either 1 irAE $(n=162), 2$ irAEs $(n=78$ or $\geq 3$ irAEs $(n=34)$, with a median exposure time of 52 days ${ }^{30-91}$ for the first irAE. Dermatological irAEs were by far the most frequent $(n=160)$, followed by digestive 
$(n=80)$, endocrine irAEs $(n=67)$, rheumatic $(n=49)$ and pulmonary irAEs $(n=17)$. So far, evaluation of tumour response was available for 551 patients, including 190 responders (complete response $n=36$ and partial response $n=154$ ), 192 patients with stable disease and 169 with progressive disease. 122/189 responders $(65 \%)$ and $107 / 192$ with stable disease (56\%) experienced at least one irAE while reported only in 40/169 non responders (24\%). Patients experiencing at least one irAE had an increased overall survival (median of 1169 days versus 224 days, $p<0,0001$, figure 1), without statistical difference according to organ system. Of note, there was also no statistical difference regarding tumour response or irAEs occurrence among the $9.4 \%$ of patients with preexisting inflammatory or autoimmune disease (60/636).

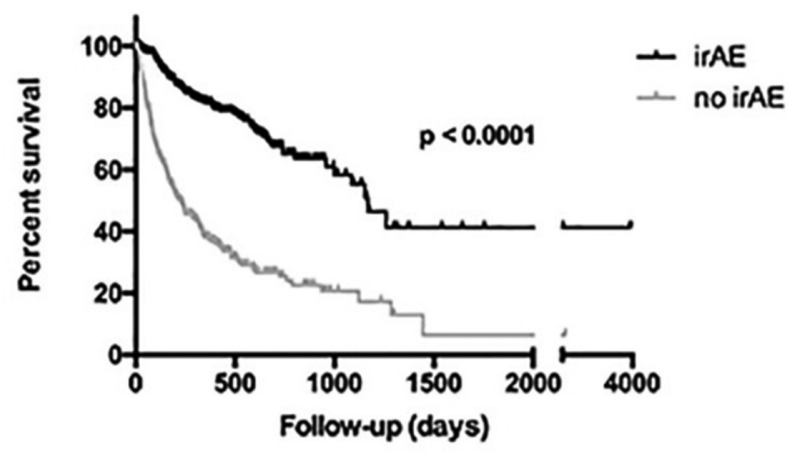

Abstract OP0088 - Figure 1. Overall survival according to irAE occurance

Conclusions: Although irAE occurrence is not required for treatment benefit, it strongly associates with overall survival. Optimal multidisciplinary management of irAEs, including rheumatologists when needed, is worthwhile to maintain beneficial responses.

Disclosure of Interest: None declared

DOI: 10.1136/annrheumdis-2018-eular.3783

WEDNESDAY, 13 JUNE 2018:

\section{New driving molecules in systemic sclerosis}

\begin{tabular}{l|l}
\hline OP0089 & ABATACEPT IS EFFECTIVE IN EXPERIMENTAL \\
DIGESTIVE AND LUNG TISSUE FIBROSIS
\end{tabular}

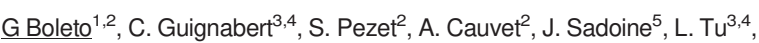
C. Nicco ${ }^{2}$, C. Gobeaux ${ }^{6}$, F. Batteux ${ }^{2}$, Y. Allanore ${ }^{1,2}$, J. Avouac $^{1,2} .{ }^{1}$ Department of Rheumatology A, Cochin Hospital; ${ }^{2}$ INSERM U1016, Institut Cochin, CNRS UMR8104, Paris Descartes University, Paris; ${ }^{3}$ Université Paris-Sud, Université Paris-Saclay, Le Kremlin-Bicêtre; ${ }^{4}$ INSERM UMR_S 999, Paris Sud University, Le Plessis-Robinson; ${ }^{5}$ EA 2496 Pathologie, Imagerie et Biothérapies Orofaciales, UFR Odontologie, Université Paris Descartes and PIDV, PRES Sorbonne Paris Cité, Montrouge; ${ }^{6}$ Clinical Chemistry Laboratory, Cochin and Hôtel-Dieu Hospitals, Paris Descartes University, Paris, France

Background: Cytotoxic T-lymphocyte associated molecule-4 (CTLA-4) is an immunoregulatory membrane receptor resulting in the down-regulation of T-cell responses. A previous report showed that abatacept (CTLA4-Ig) prevented and induced regression of inflammation-driven dermal fibrosis in two different mouse models of systemic sclerosis (SSc). ${ }^{1}$

Objectives: We aimed to assess the effects of abatacept in two complementary mouse models reflecting digestive involvement, lung fibrosis and pulmonary hypertension $(\mathrm{PH})$, mimicking severe SSc organ damage.

Methods: Abatacept was given in the chronic graft-versus-host disease (cGvHD) mouse model, characterised by digestive involvement, and in the Fra-2 mouse model which is characterised by non-specific interstitial pneumonia and pulmonary vascular remodelling leading to $\mathrm{PH}$. Mice were treated by intraperitoneal injections of abatacept $(1 \mathrm{mg} / \mathrm{mL}$ in the cGvHD model for 6 weeks; $1 \mathrm{mg} / \mathrm{mL}$ or $10 \mathrm{mg} / \mathrm{mL}$ in the Fra-2 mouse model for 4 weeks) or human lgG1 (100 mg) used as a negative control.

Results: In the cGvHD model, treatment of allogeneically mice with abatacept led to a significant reduction of alanine aminotransferase $(24 \%, \mathrm{p}=0.014)$ and aspartate aminotransferase levels $(61 \%, p<0.001)$. Pathological analysis of colon revealed decreased inflammatory infiltrates and destruction of crypts in allogeneically mice receiving abatacept.
When assessed by chest micro-CT imaging, Fra-2 mice treated with abatacept displayed a $12 \%$ decrease in lung density $(10 \mathrm{mg} / \mathrm{ml}, \mathrm{p}=0.037)$ as well as an increase in functional residual capacity as compared to lgG1-treated mice (16\% for $1 \mathrm{mg} / \mathrm{ml}, \mathrm{p}=0.001 \%$ and $14 \%$ for $10 \mathrm{mg} / \mathrm{ml}, \mathrm{p}=0.005$ ).

Consistent with these results, abatacept $10 \mathrm{mg} / \mathrm{L}$ decreased histological fibrosis score (Ashcroft score) as well as hydroxyproline content by $79 \%(p=0.009)$ and $31 \%(p=0.044)$ respectively, as compared to IgG1-treated mice.

Treatment with abatacept $10 \mathrm{mg} / \mathrm{mL}$ markedly reduced protein levels in the lesional lungs of Fra-2 mice of the fibrogenic markers MCP1 by $79 \%(p=0.043)$ and osteopontin by $87 \%(p=0.039)$. Levels of TGF-b were also reduced with abatacept $(61 \%$ for $1 \mathrm{mg} / \mathrm{mL}, \mathrm{p}=0.037 \%$ and $69 \%$ for $10 \mathrm{mg} / \mathrm{mL}, \mathrm{p}=0.013)$. Further, abatacept decreased M1 and M2 macrophages infiltration as well as T-cell proliferation in the lesional lungs of Fra-2 mice.

Upon treatment with abatacept a reduction of right ventricular systolic pressure (28.1 $\pm 1.5 \mathrm{mmHg}$ vs $36.0 \pm 5.1 \mathrm{mmHg}, \mathrm{p}=0.037$ for $10 \mathrm{mg} / \mathrm{mL}$ ) and right ventricular hypertrophy $(0.29 \pm 0.01$ vs $0.33 \pm 0.010, p=0.037$ and $29 \pm 0.01 \%$ vs $0.33 \pm 0.01 \%$ for $10 \mathrm{mg} / \mathrm{mL}, p=0.037$ ) was observed compared to lgG1-treated mice. Consistent with these findings, abatacept $10 \mathrm{mg} / \mathrm{mL}$ was associated with significant decrease in percent medial wall thickness and numbers of muscularized distal pulmonary arteries.

Conclusions: We demonstrate that treatment with abatacept improves digestive involvement, prevents lung fibrosis and attenuates $\mathrm{PH}$ in SSc pre-clinical mice models. These findings suggest that abatacept might be an appealing therapeutic approach for severe internal organ involvement in SSc beyond its already demonstrated effects on skin fibrosis.

\section{REFERENCE:}

[1] Ponsoye M, et al. Ann Rheum Dis 2016 Dec;75(12):2142-9.

Disclosure of Interest: None declared

DOI: 10.1136/annrheumdis-2018-eular.2545

\section{OP0090 MITOCHONDRIAL DNA MUTATIONS AND RESPIRATORY CHAIN DYSFUNCTION IN LUNG FIBROSIS OF SYSTEMIC SCLEROSIS}

V.K. Jaeger ${ }^{1}$, D. Lebrecht ${ }^{2,3}$, A.G. Nicholson ${ }^{4,5}$, A.U. Wells ${ }^{4,6}$, S. George ${ }^{7}$, A. Gazdhar ${ }^{8}$, M. Tamm ${ }^{9}$, N. Venhoff ${ }^{3}$, T. Geiser ${ }^{10}$, U.A. Walker ${ }^{1}{ }^{1}$ Department of Rheumatology, University Hospital Basel, Basel, Switzerland; ${ }^{2}$ Department of Pediatrics and Adolescent Medicine, Division of Pediatric Hematology and Oncology, Medical Center, Faculty of Medicine, University of Freiburg; ${ }^{3}$ Department of Rheumatology and Clinical Immunology, Faculty of Medicine, University of Freiburg, Freiburg, Germany; ${ }^{4}$ National Heart and Lung Institute, Imperial College; ${ }^{5}$ Department of Histopathology; ${ }^{6}$ Interstitial Lung Disease Unit, Royal Brompton Hospital, Royal Brompton and Harefield NHS Foundation Trust, ${ }^{7}$ Royal Brompton and Harefield NHS Foundation Trust, London, UK; ${ }^{8}$ Department of Pulmonary Medicine, University Hospital Bern, Bern; ${ }^{9}$ Department of Pneumology, University Hospital Basel, Basel; ${ }^{10}$ Department of Pneumology, University Hospital Bern, Bern, Switzerland

Background: Recent data have implemented reactive oxygen species (ROS) in the etiology of interstitial lung disease (ILD) in systemic sclerosis.

Objectives: To investigate a role of large-scale somatically acquired mutations in mitochondrial DNA (mtDNA) and consecutive respiratory chain dysfunction as a trigger of ROS formation and lung fibrosis.

Methods: Lung biopsies from patients with idiopathic interstitial pneumonitis and systemic sclerosis $(n=31)$ were analysed for mitochondrial functions and com pared with biopsies from 13 healthy controls $(\mathrm{HC})$. From 17 patients we had simultaneous biopsies from the upper and lower lung.

Results: Malondialdehyde as a marker of ROS formation was increased in ILD $(p=0.007)$. The median proportion of mtDNA containing the pathogenic common deletion was $22.5 \%$ in ILD patients, compared to $0 \%$ in $\mathrm{HC}$. This translated into a 3.8-fold diminishment of mtDNA-encoded cytochrome c-oxidase (COX2), but not nucleus-encoded (COX4) respiratory chain subunits in ILD compared to controls $(p<0.0001)$ and a $33 \%$ diminishment of mtDNA-encoded cytochrome c-oxidase activity ( $p=0.001 \mathrm{vs}$ controls). In all patients, the more fibrotic lower lungs had significantly more malondialdehyde $(p=0.0004)$, mtDNA deletions $(p=0.0006)$, and cytochrome $c$-oxidase dysfunction $(p=0.0003)$ than the less-fibrotic upper lung counterparts. Conversely, lower lungs had significantly less $(p=0.0003)$ mtDNA encoded COX2 subunits in comparison to non-mtDNA-encoded COX4 subunits (figure 1). There was no association of any mitochondrial parameter with smoking status or age, and no difference between biopsies from patients with systemic sclerosis and non-specific interstitial pneumonitis. 